\title{
The Coach Profile and the Implementation Program of the Training Period Between the Age Group < 19 Years (Yunior) at Volleyball Clubs in Yogyakarta Special Region
}

\author{
Fatkurahman Arjuna ${ }^{1,{ }^{*}}$ M. Furqon Hidayatullah ${ }^{1,}$ Sugiyanto Sugiyanto ${ }^{1,}$ Muchsin
}

Doewes $^{1}$

\author{
${ }^{1}$ Faculty of Sports Universitas Sebelas Maret \\ arjuna@student.uns.ac.id ${ }^{l,}$ furqon@.fkip.uns.ac.id,,'sugiyantoprobo@gmail.com,'.mdoewes2000@yahoo.com.'I
}

\begin{abstract}
The purpose of this study was to determine the profile of the Coach consisting of [age, training experience, formal education and trainer license] and the implementation of the training periodization program consisting of reference to the physical exercise book owned, the application of physical exercise according to the energy system characteristics needed of the voleyball players aged $<19$ years/junior and the implementation of a periodization program of physical exercise. This research methode is used a survey method by conducting direct interviews with volleyball coaches aged $<19$ years [juniors]. This research was conducting from February to August. The subjects in this study obtained 40 volleyball coaches aged $<19$ years [juniors].The results of this research interviews with the data obtained are as follows: 1. Age 56 years with an average age of 33 years, [b] training experience varies at least 1 year and maximum 21 years with an average training experience of 5.5 years, [c] formal education 14 [35\%]trainers have a high school education, 22 [55\%] have a bachelor's degree [S1] and $4[10 \%]$ have a master's degree [S2]. and [d] licensed trainers as many as $21[52 \%]$ licensed trainers, 13 [32.5\%] licensed trainers and 6 [15\%] National $\mathrm{C}$ licensed trainers. 2. Implementation of exercise periodization, namely: [a] as many as 13 [32.5\%] trainers have a manual and 27 [67.5\%] trainers do not or yet have a manual in training physical conditions. [b] The application of physical exercise is adjusted to the characteristics of the energy system in ball games as many as 13 [32.5\%] coaches stated that they had implemented it, 25 [62.5\%] coaches stated that they had not fully implemented it and $2[5 \%]$ said that they had not implemented it. [c] Implementation of exercise periodization as many as 26 [65\%] trainers did not create and implement training periods and as many as $2[5 \%]$ trainers stated that they did not make and do the exercise periodization implementation.
\end{abstract}

Keywords: Profile of the volleyball coaches, training periodization, and volleyball players, aged $<19$ years (junior)

\section{INTRODUCTION}

The successful athletes who are trained, excel in certain physical activities, through tiered preparation, and follow a long-term program [1]. Coaches have an important role in supporting athletes' achievements to be able to bring out all their potential. Decision making is an important task in managing training programs, coaches must be able to decide what physical exercise should be used for improving the most efficient performance for their students [2].
The coach's profile is important to know as an indicator coach's ability to carry out his duties as a coach. These indicators can be seen from age, length of training, formal education and non-formal education. The coach ability to implementing an exercise program can be obtained either through formal or non-formal education. Formal education is pursued through formal training institutions such as universities, while nonformal education is obtained when becoming an athlete or attending training seminars. 
Implementing an exercise periodization program is very important because the core of the training theory is the idea that a structured training system can form and combine training activities for target psychological and individual characteristics in a particular sport [3]. Trainers who have the ability and knowledge about bioenergy, and implementing a joint exercise program in physical adaptation will have a greater chance of being able to develop an effective exercise plan.

Volleyball game has a strong and fast character, therefore the most important physical components to have are strength and power [4]. In volleyball games are prone to injury due to the character of the game that requires strength and power. Training phase more injuries are reported [5]. Prevention of sports injuries in adolescents is important and therefore the significant impact of injury on the population deserves special attention.

Volleyball players aged 15-19 years are in the category of junior players or the age of adolescence. The adolescent period is a period where changes are mostly happen, both hormonal, physical, psychological and social changes [6]. The dolescence is a period of highest vulnerability due to high emotional, cognitive and behavioral levels, this will affect differences in judgment, decision making and risk taking in the search for identity [7]. By looking at these problems, it is necessary to research on the coach's profile to see the maturity of the coach in carrying out his coaching duties and also the application of training periodization to be able to optimize the potential of volleyball players, especially those aged $<19$ years [juniors].

\section{METHOD}

This research is using descriptive qualitative approach. Using a survey method by conducting direct interviews with volleyball coaches in the age group $<19$ years [juniors]. This research was conducted from February to August. The subjects in this study were 40 volleyball coaches in the age group $<19$ years [junior].

\section{RESULT}

This study interviewed about 40 coaches and obtained results regarding coach profiles and program implementation for soccer players aged $<19$ years [junior]. The description of the results of the trainer profile interview and the implementation of the periodization program are as follows:

\subsection{Profile of volleyball coach age group $<19$ Years [Junior] Special Region of Yogyakarta}

3.1.1. Volleyball coach age group $<19$ years old [junior] Special Region of Yogyakarta the interview result with volleyball coaches obtained data as follows: the age of volleyball coaches in the Special Region of Yogyakarta who handles the age group $<19$ years [juniors] varies from the youngest age 20 years and the oldest age 56 years with an average age of 33 years.

3.1.2. The coach Experience in coaching volleyball for the age group $<19$ years [juniors] Special Region of Yogyakarta the interview result with volleyball coaches, the following data was obtained from the experience of training or working to deal with soccer players aged $<19$ years [juniors]. The average training experience is about 5.5 years.

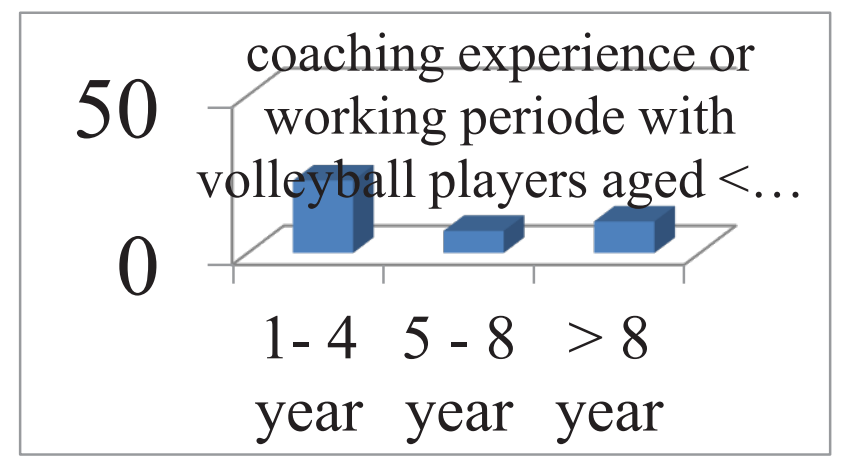

Figure 1 Graph of experience in coaching or working with volleyball players aged $<19$ years [juniors] in the Special Region of Yogyakarta.

3.1.3. Volleyball coach age group $<19$ years old [junior] Special Region of Yogyakarta the interview result with volleyball coaches obtained data as follows: the age of volleyball coaches in the Special Region of Yogyakarta who handles the age group $<19$ years [juniors] varies from the youngest age 20 years and the oldest age 56 years with an average age of 33 years.

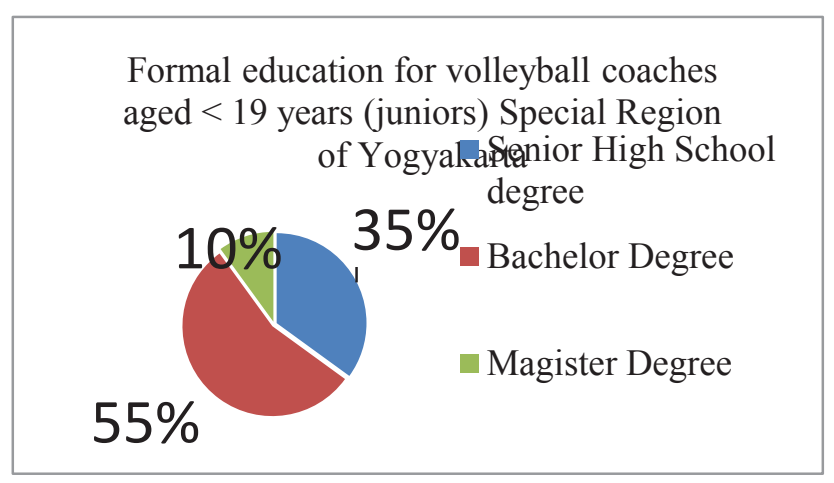

Figure 2 Graph of Formal Education of Volleyball Club Coaches in the Special Region of Yogyakarta Age Group $<19$ Years [Junior].

3.1.4. Coaching license owned by a volleyball coach for the age group $<19$ years [junior] Special Region of Yogyakarta. The results of interviews with volleyball coaches obtained the following 
data. Coaching licenses owned by volleyball coaches in the age group $<19$ years [juniors] Special Region of Yogyakarta, from a total 40 samples of coaches, about 21 unlicensed coaches were obtained, as many as 13 local-level licensed trainers and 6 coaches owned a National C licensed trainer.

Coaching license owned by a volleyball coach for the age group $<19$ years (junior) Special Region of Yogyakarta.

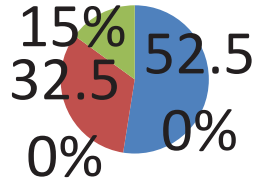

Un Licenced

Figure 3 Volleyball Club Coach License in the Special Region of Yogyakarta Age Group $<19$ Years (Junior).

\subsection{The Training Periodization Implementation Program for Volleyball Players Age $<19$ Years (Junior) Special Region of Yogyakarta}

The results of interviews with 40 coaches with the following statement: they have implemented exercises according to the characteristics of the volleyball game system. as many as 25 trainers stated that they had not fully implemented it and as many as 2 coaches stated that they had not implemented it at all.

Ownership of Reference Books for Application of Physical Exercise Models for Volleyball Players Age $<19$ Years in

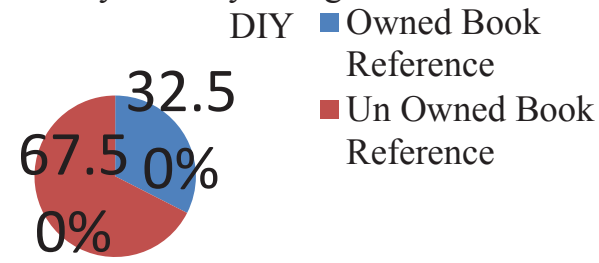

Figure 4 Reference to physical training reference books owned by volleyball coaches in the age group $<19$ years (juniors) Special Region of Yogyakarta

\subsubsection{Implementation of physical exercise in accordance with the energy system characteristics and the needs of soccer players aged < 19 years (juniors) Special Region of Yogyakarta}

The results of interviews with 40 coaches with the following statement: they have implemented exercises according to the characteristics of the volleyball game system. as many as 25 trainers stated that they had not fully implemented it and as many as 2 coaches stated that they had not implemented it at all.

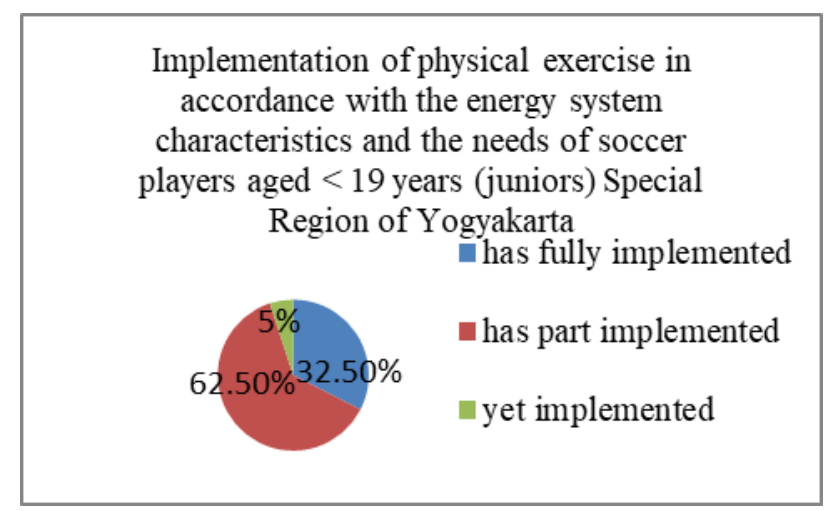

Figure 5 The Implementation of physical exercise according to the characteristics of the energy system according to the needs of volleyball players aged $<19$ years (juniors) Special Region of Yogyakarta.

\subsection{Implementation of the physical exercise periodization program that has been made}

The results of interviews with volleyball coaches aged $<19$ years (juniors in the Special Region of Yogyakarta related to the program and the implementation of the periodization of physical exercise applied to volleyball players aged $<19$ years [juniors] in the Special Region of Yogyakarta obtained the following data: 26 coaches states always make and apply the periodization of physical exercise. 12 trainers stated that they did not create and implement physical exercise periodization and as many as 2 trainers stated that they did not always create and implement physical exercise periodization.

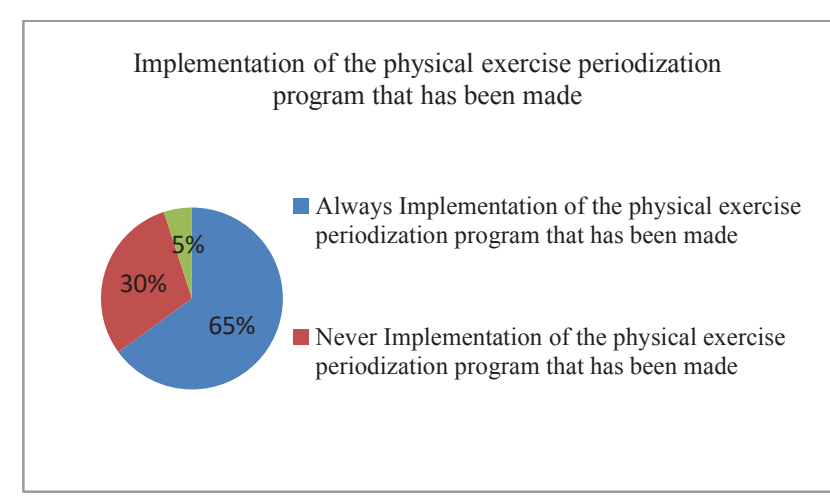

Figure 6 Creating and Implementing Physical Exercise Periodization Programs.

\section{DISCUSSION}

Based on the results of interviews with 40 volleyball coaches in the age group $<19$ years (juniors) from the Special Region of Yogyakarta regarding the coach's profile and the implementation of the training periodization program, different results were obtained. 


\subsection{Profile of Volleyball Coach Age Group < 19 Years (Junior) Special Region of Yogyakarta.}

\subsubsection{Coach Ages}

The average age of volleyball coaches in the age group $<19$ years (juniors) is about 33 years. This result proves that volleyball coaches are of a mature age. This age maturity will encourage trainers to be able to adapt to technology where all forms of research and development are on the internet. coaches will easily access the latest international journals and e-books.

\subsubsection{Training Experience}

One part of the successes in coaching is having experience in coaching. More longer experience of training, coache will have more abilities to analyze the shortcomings and weaknesses in making the exercise program they are undergoing. The average experience of training volleyball in the Special Region of Yogyakarta is 5.5 years, which means that many evaluations have been carried out in implementing the training periodization program.

\subsubsection{Formal Education}

Formal education can directly affect the training program and variations in the making of physical exercise programs. The ability to train can be obtained from formal and non-formal education. Formal education is taken through college, while non-formal education is obtained from being an athlete, or sports coaching seminars. Total of 22 coaches have a bachelor's degree in sports means that more than $50 \%$ of coaches have developed their coaching skills from formal education and even 4 coaches have a master's degree. Couches should always be required to develop their training skills from both formal and non-formal education. For coaches who do not have a bachelor's degree, it is recommended to be able to attend sports training or seminars, especially volleyball so that their training abilities always follow the development of science that continues to develop.

\subsubsection{Coaching License}

Coaching license is needed to support a coach's career, inclode volleyball coaches. From the results of interviews obtained data as many as $21(52 \%)$ of the coach are not yet licensed. One of the tasks of the coach is to increase knowledge and skills [8]. 21 coaches who do not yet have a license are advised to take part in training on coach licenses, both regional and national, in collaboration with PBVSI PEMCAB and regional governments. It is hoped that these couches have licenses that can be used in the future either to train at a higher level or to train conditions.

\subsection{Implementation of the Training Periodization Program for Volleyball Players Age $<19$ Years (Junior) Special Region of Yogyakarta}

\subsubsection{Ownership of reference books that are a reference for physical exercise}

One part of coach duty is to increase knowledge and skills by attending training courses or by increasing the number of reference books, journals and research conducted. From the results of interviews with 40 volleyball coaches, the following data were obtained: as many as 13 coaches had a manual and 27 (67.5\%) coaches did not have a manual in training physical conditions. More than $50 \%$ of coaches do not have a reference book in volleyball practice, of course this will be very detrimental to both coaches and students. The main task of the coach is to direct, guide, educate and help reveal the athlete's potential. The more books, journals and research, the more focused the coach's task will be, the implementation of sport science can run well and the results will also be maximized.

\subsubsection{Implementation of physical exercise adapted to energy system characteristics of the in volleyball games}

The coach, before their compiling the program need to analyze the characteristics and branches of the sport he is engaged in. From the results of interviews with 40 coaches, there are 25 coaches $(62.5 \%)$ who have not fully implemented it, 2 coaches $(5 \%)$ stated that they have not fully implemented it and only 13 coaches have applied energy in ball games. The each sport has characteristics and advantages of energy systems that are different from one another [9].

Based on the analysis, the coach will determine the differences in material requirements and methods required by each sport, especially volleyball which requires strong motion and high strength. Trainers who have not implemented training according to the characteristics of the ball game as many as 27 coaches are advised to analyze the characteristics and the main energy system because it will be very useful in supporting the sports performance they want. Characteristics of ball sports that need to be considered are: predominance of the energy system, predominance of biomotor, type of muscle, extremities and muscles that work, duration of the match, type of motion, type of field, techniques and tactics in volleyball.

\subsubsection{Implementation of exercise periodization}

The periodization of training is a description of the phasing of the material, load, targets and training methods carried out, so that the player's peak performance goals can be achieved on time [8]. The purpose of physical exercise is to improve muscle fitness and energy fitness. Each training objective must 
refer to the periodization time that is being undertaken as well as in the physical training of volleyball games. From the results of interviews with 40 trainers, the following data was obtained: $12(30 \%)$ trainers stated that they did not make and implement exercise periodization, as many as $2(5 \%)$ trainers did not always make and implement. 14 (35\%) volleyball coaches did not arrange and implement training periodization. Volleyball coaches are expected to always compile and implement training periodization in order to have an overview in providing materials, loads, targets and training methods, so that the player's peak performance goals can be achieved on time. The physical exercise program can run well because the trainer already has guidelines and is not impressed at all in the implementation of each physical training session.

\section{CONCLUSION}

A coach is person who has the ability professionally to be able to help reveal the potential of athletes into real abilities optimally through a tiered training program. One of the things that must be owned by a coach is knowledge and experience in their field, as well as volleyball coaches. The profile of volleyball coaches in the age group $<19$ years (juniors) in DIY is quite good but needs to be improved in terms of knowledge and experience of coaching license competence. The application of PBVSI training periodization is expected to provide an intervention to the trainer in making the exercise periodization program. PBVSI is expected to be able to provide training or provide books, dictation and training so that the implementation of training periodization can run well. The support of the PBVSI of the district and local governments is very much needed in order to advance volleyball in the Special Region of Yogyakarta.

\section{REFERENCES}

[1] Bompa Tudor and Michael Carrera, Conditioning Young Athletes. United States of America: Human Kinetics, 2015.

[2] Gustavo Leporace et al, "Influence Of A Preventive Training Program On Lower Limb Kinematics And Vertical Jump Height Of Male Volleyball Athletes", BMC Research Notes, 2012.

[3] Bompa Tudor and Gregori Haff, Periodization Theory and Methodology of Training. United States of America: Human Kinetics, 2009.

[4] Russell R Pate, Bruce Mcclenaghan and Robert Rotella, Scientific Foundations of Coaching. Amerika Serikat: Sauders College Pusblising, 1993.

[5] Franciele Marques Vanderlei, Fabio Nascimento Bastos and Gustavo Yuki Cantalejo Tsutsumi, "Characteristics And Contributing Factors Related to Sports Injuries in Young Volleyball Players", BMC Research Notes, 2013.

[6] Jose RL Batubara, "Adolesencent Development (Perkembangan Remaja)", Sari Pediatri, 2010, vol. 12 , no. 1, pp. 21-29.
[7] Laurence Steinberg, "Cognitive and affective development in adolescence", TRENDS in Cognitive Sciences, 2005, vol. 9, no. 2, pp. 69-74.

[8] Sukadiyanto, Pengantar Teori dan Metodologi Melatih Fisik, Yoyakarta: Universitas Negeri Yogyakarta, 2009.

[9] Emral, Pengantar Teori dan Metodologi Pelatihan Fisik. Depok: Prenada Media, 2017. 